\title{
Criar e compartilhar games: novas possibilidades de letramento digital para crianças surdas *
}

\author{
Patrícia Rocha Rodrigues, PPGEduc/UNEB, rochapatricia.r@gmail.com \\ Lynn Rosalina Gama Alves, PPGEduc/UNEB, SENAI/CIMATEC, lynnalves@gmail.com
}

Resumo: Este trabalho apresenta uma pesquisa que tem por objetivo analisar a emergência de práticas de letramento digital de crianças surdas na construção de jogos digitais, a partir da mediação do software Scratch. A relevância desse estudo justifica-se pelo fato de apresentar uma análise aprofundada dos processos de letramento ocorridos durante a pesquisa, trazendo contribuições importantes para orientar as práticas pedagógicas destinadas a alunos surdos. Tratou-se de uma pesquisa participante, de abordagem qualitativa, realizada em duas etapas. A primeira seguiu um roteiro de atividades de observação das práticas de letramento digital que os sujeitos já possuíam. A segunda, consistiu em oficinas de construção de jogos digitais utilizando o ambiente Scratch. Participaram da pesquisa, seis crianças surdas do $4^{\circ}$ do ensino fundamental que frequentam o Atendimento Educacional Especializado (AEE) em um centro de apoio à educação inclusiva, com idade entre 10 e 12 anos. A escolha do grupo considerou seu bom nível de comunicação em língua de sinais e o fato de estarem em processo inicial de aprendizado da escrita. Como resultado, verificou-se que as oportunidades de expressão e interação em práticas de letramento multimodais presentes no ambiente Scratch favoreceram a ampliação de habilidades de letramento digital desses alunos.

Palavras-chaves: letramento digital, surdez, jogos digitais.

\section{Creating and sharing games: new possibilities of digital literacy for deaf children}

Abstract: This paper presents a survey that intends to analyze the insertion of practical of digital literacy for deaf children from the construction of digital games using Scratch software. The relevance of the study is based on a deep analysis about process of literacy during the research, bringing important contributions in other to guide pedagogic practices aimed at deaf students. This is a survey with qualitative analyzes, which was performed with two steps. The first of them followed a script with observational activities of the practices of digital literacy already held by individuals. The second is in workshops about construction of digital games using the Scratch software. Participated in the survey, six deaf children of forth grade, between ten and twelve years old. All of them attend the Specialized Educational Services in a support center for inclusive education. These children also have a good level of communication in signal language, besides being in the initial process of writing learning. As results, it is visible how opportunities of expression and interaction in literacy practices using Scratch favor expansion of skills for these students.

Keywords: digital literacy, deafness, digital games.

\section{O CONTEXTO DA PESQUISA}

Um dos grandes desafios para os processos educativos destinados aos surdos tem sido garantir sua inclusão nas práticas culturais de letramento. Isso por que, devido às especificidades desses alunos na área da linguagem, muitos acabam por enfrentar dificuldades de interação com os sistemas simbólicos, principalmente a escrita, comprometendo sua participação em diferentes contextos e ambientes sociais.

No entorno dessa problemática, encontram-se as atuais alterações nas condutas comunicativas e na interação com o conhecimento instauradas com a ampliação da presença das tecnologias digitais e telemáticas em diferentes espaços sociais. Nessa nova realidade, as maneiras de acessar e produzir significados não se concretizam mais exclusivamente sob a forma da escrita e na cultura de hoje, mais do que nunca, múltiplas

\footnotetext{
* Trabalho resultante da pesquisa de mestrado intitulada "Práticas de letramento digital de alunos surdos no ambiente Scratch” sob orientação da Dr. a Lynn Alves (UNEB, 2013-2015).
} 
linguagens se misturam provocando modificações na forma como nos comunicamos. Surge daí, um novo paradigma de letramento, o digital, marcado por novas formas de interação, competências discursivas e cognitivas.

A participação dos surdos nos ambientes digitais já tem sido registrada por alguns estudos que destacam as possibilidades que se abrem para sua inclusão social e aprendizado (Arcoverde, 2006; Machado; Feltes, 2010, e outros). Entretanto, é importante destacar que esses trabalhos atêm-se a participação de jovens e adultos surdos, havendo assim uma lacuna investigativa a respeito da atuação das crianças.

A partir dessas circunstâncias, e do envolvimento profissional com a educação de surdos por parte de uma das autoras deste artigo, é que surgiu a pesquisa de mestrado aqui referenciada, cujo objetivo principal consistiu em analisar a emergência das práticas de letramento digital de seis crianças surdas, com idade entre 10 e 12 anos, na construção de jogos digitais, a partir da mediação do software Scratch. A investigação desse processo permitiu o levantamento de questões relacionadas às especificidades da surdez nos ambientes digitais, considerando não apenas as dificuldades que essa condição particular apresenta, mas, principalmente refletindo sobre o caráter potencial que se inaugura em nossos tempos.

O Scratch ${ }^{1}$ foi escolhido por ser um software gratuito que permite, especialmente crianças e adolescentes criarem histórias interativas, jogos e animações através da linguagem de programação gráfica (ver Figura 1), além de permitir o compartilhamento de suas criações na internet, inclusive em uma comunidade online que atua como rede social ${ }^{2}$. Delimitouse o âmbito dos jogos digitais como atividade central por ser um tema que povoa o universo infantil e adolescente, sendo ainda compreendidos nesta pesquisa como elementos importantes nos processos de socialização e de promoção de eventos de letramento, que podem gerar novos modos de perceber, aprender e de se expressar (Alves, 2010).

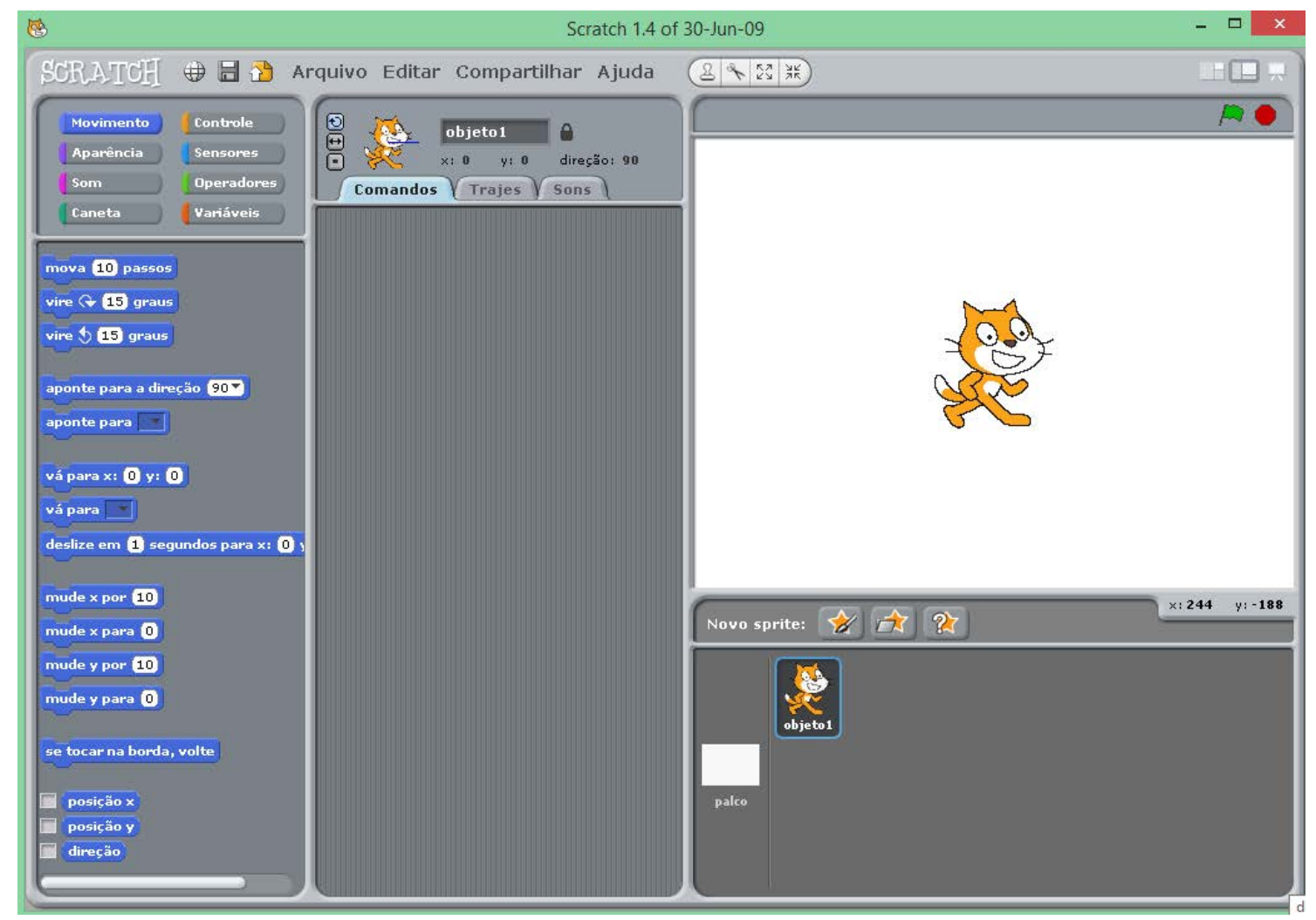

Figura 1 - Interface gráfica do Scratch 1.4 
A proposta investigativa desenvolveu-se a partir do método de pesquisa participante, seguindo uma abordagem qualitativa, subdividindo-se em duas etapas. A primeira delas pretendeu observar e avaliar as práticas de letramento digital que os sujeitos já possuíam. Para isso, foi utilizado um roteiro de atividades, com a temática dos jogos digitais, que incluiu pesquisa e exploração em sites da internet, publicação e compartilhamento de informações em blog e redes sociais, uso de e-mails, chats e espaços de afinidade. $\mathrm{O}$ desempenho das crianças nessas atividades foi avaliado segundo alguns critérios estabelecidos a partir da fundamentação teórica adotada, sendo possível identificar um nível básico de habilidades relacionadas ao letramento digital.

Na segunda etapa, a partir do desenvolvimento de oficinas de construção de jogos digitais utilizando o ambiente Scratch, foi possível acompanhar os processos de imersão, interação e letramentos ocorridos, registrando e analisando a evolução da qualidade participativa das crianças nos espaços digitais. Essas oficinas foram organizadas durante o AEE da Associação de Pais de Amigos de Deficientes Auditivos do Estado da Bahia (APADA-BA), sendo distribuídas em encontros semanais ao longo dos meses de outubro a novembro de 2013, com carga horária total de vinte horas. O grupo de sujeitos escolhidos para participar da pesquisa foi composto por estudantes do $4^{\circ}$ ano do ensino fundamental, considerando seu bom nível de comunicação em língua de sinais e o fato de estarem em processo inicial de aprendizado da escrita.

Uma vez que a proposta investigativa surgiu do envolvimento profissional de uma das autoras desse artigo com os sujeitos da pesquisa, o trabalho foi conduzido numa perspectiva de construção e gestão de saberes sobre a realidade educativa a que estava inserido, buscando instituir uma experiência pautada na observação e interpretação das ações a partir do ponto de vista das pessoas que as praticam. Desta forma, o estudo alinhou-se aos fundamentos e procedimentos da etnopesquisa crítica (Macedo, 2004), tendo como principal instrumento de coleta de dados o diário de pesquisa, onde foi feito um registro minucioso das atividades desenvolvidas.

Para a análise da experiência e dos materiais produzidos, observou-se protocolos e critérios estabelecidos a partir de duas categorias analíticas: letramento digital e autoria. Essas categorias permitiram ainda uma abordagem aprofundada de questões relacionadas à inclusão dos surdos na cultura digital, refletindo sobre as especificidades tanto com relação às dificuldades, quanto às possibilidades que emergem nesse contexto.

\section{ENTRELAÇAMENTO TEÓRICO}

Há muito que a leitura e a escrita se instituem como práticas cotidianas intrínsecas às atividades sociais do ser humano, exigindo dele habilidades específicas para os processos de compreensão, interpretação, ressignificação e produção de sentidos. De fato, a cultura letrada é um bem social indispensável para enfrentar o cotidiano. É nesse contexto que se dá a construção do letramento, compreendido por Kleiman (2010) como amplo fenômeno de práticas sociais que usam a língua escrita.

Com o advento das tecnologias digitais e telemáticas, essas práticas se alteraram, configurando novas formas de interação, competências discursivas e cognitivas, e, delimitando funções essenciais para a participação ativa e competente dos sujeitos envolvidos. Para alguns autores (Soares, 2002; Xavier, 2007 e outros), presenciamos assim, o surgimento de um novo paradigma de letramento: o letramento digital.

O letramento digital implica realizar práticas de leitura e escrita diferentes das formas tradicionais de letramento e alfabetização. Ser letrado digital pressupõe assumir mudanças nos modos de ler e escrever os códigos e sinais verbais e não-verbais, como imagens e desenhos, se 
compararmos às formas de leitura e escrita feitas no livro. (Xavier, 2007, p. 2)

Os estudos sobre o letramento digital têm se revelado como uma área rica e desafiadora. Contudo, como aponta Ribeiro (2009), há controvérsias a respeito do termo usado, como também com relação ao conceito envolvido. É possível encontrar, assim, expressões como letramento informacional, alfabetização digital, letramento midiático, entre outras, como sinônimos ou ainda com variações conceituais decorrentes do referencial teórico adotado. De acordo com Araújo e Frade (2007) os primeiros registros relacionados a esse âmbito faziam referência a uma concepção voltada para o aprendizado das técnicas de uso de aplicativos como planilhas eletrônicas e editores de texto. Por outro lado, outras abordagens reconhecem que as tecnologias digitais levaram a marcantes transformações em termos de recursos disponíveis para a construção de significados (fala, escrita, imagem, música e outros) e também nas formas de utilização desses mesmos recursos para comunicar e disseminar os significados. Ou seja, alteram-se as formas como comunicamos e escrevemos, como interagimos e com quem interagimos (Jenkins et al., 2009).

Essa perspectiva desloca-se dos aspectos puramente instrumentais comumente relacionado ao uso das tecnologias digitais e telemáticas. Nesse sentido, a abordagem cultural de Lévy (2011) contribui para desmistificar as tecnologias como apenas ferramentas, ao destacar que existe um imbricamento entre esses recursos e a própria ecologia cognitiva da espécie humana. Para esse autor, elas devem ser entendidas como tecnologias intelectuais, uma vez que possibilitam a reorganização e modificação dos meios nos quais se propagam as representações cognitivas dos indivíduos. Tais representações manifestam-se de modo particular a cada recurso tecnológico com o qual o sujeito interage, o que pode ser tanto uma tecnologia digital, como até mesmo outros tecnologias já tradicionalmente enraizadas na história da humanidade, como a oralidade e a escrita.

Isto posto, é possível discutir o letramento digital a partir de uma concepção relacional de letramento, articulando-o com o campo teórico dos multiletramentos (Cope; Kalantzis, 2009). No âmbito desse debate, destaca-se a evidência de que no mundo globalizado e altamente tecnológico da atualidade, a diversidade e pluralidade cultural e semiótica permeiam cada vez mais as práticas comunicativas sociais. Proliferam-se hoje as maneiras multimodais de produzir significados, em que as palavras escritas dialogam com o visual, o sonoro e o espacial. É portanto, nesse contexto, que a própria noção de letramento associada apenas às habilidades de escrita não corresponde mais aos diferentes tipos de representação que circulam hoje. Para Dionísio, a atualidade traz novas demandas para o sujeito letrado que deve "ser capaz de atribuir sentidos a mensagens oriundas de múltiplas fontes de linguagem, bem como ser capaz produzir mensagens, incorporando múltiplas fontes de linguagem.” (Dionisio, 2006, p. 131)

Os estudos desenvolvidos pela Semiótica Social (Kress, 2013) trazem também contribuições que fortalecem a compreensão das alterações específicas às práticas de letramento digital, na medida que caracterizam os processos de construção de significados a partir de práticas multimodais. De acordo com Kress (2013), a multimodalidade referese a ações comunicativas que mobilizam, no mínimo, dois códigos diferenciados, como por exemplo, imagens e palavras, ou músicas e gestos. As possibilidades de significação oferecidas nos ambientes digitais são marcadamente multimodais, uma vez que os significados se constituem a partir de uma malha inextricável de signos moventes, reagentes, sensíveis às intervenções dos usuários, que não se restringem apenas à linguagem verbal. 
Eis portanto, a atual condição que se impõe a contemporaneidade: novas demandas de letramento e, consequentemente, novos desafios para as propostas educacionais deste século.

As discussões com relação ao letramento de surdos têm se beneficiado desse embasamento teórico para levantar questões importantes à educação desses indivíduos. Mesmo que não tratando especificadamente sobre os ambientes digitais, Fernandes (2006) e Gesueli (2012) já apontam considerações sobre o valor do letramento multimodal para esses alunos. Fernandes (2006) defende que a apropriação do sistema de escrita da Língua Portuguesa pelo surdo deve ocorrer sob a perspectiva do letramento, como prática situada e funcional, através da incursão visual e significativa, uma vez que esses indivíduos leem o mundo de forma visual. Gesueli (2012), por sua vez, aponta a relevância de se conceber o letramento na surdez como um processo multimodal caracterizado pelo uso de mais de um código semiótico, atravessado por formas múltiplas de significação. Essa autora, apoiada na abordagem de Krees, enfatiza que o processo de significação, próprio do letramento, depende dos signos disponíveis para o sujeito surdo. Estudos mais específicos que procuram avaliar as formas de participação desses indivíduos nos ambientes digitais (Rosa; Cruz, 2001; Machado; Feltes, 2010; Nogueira, 2014, entre outros) têm indicado que as práticas multimodais que abundam nesses ambientes favorecem o engajamento de surdos como verdadeiros agentes de letramentos. Justamente por que nos ambientes digitais os significados emergem de modos variados, multimodais, não restritos à linguagem verbal, mas a uma mistura densa e complexa de linguagens (incluindo a visual), os surdos encontram formas de participar e ter acesso a um universo sígnico.

Essa participação, tem colocado esses sujeitos não apenas no lugar de receptor, mas também de autor. É o que comprova o trabalho de Nogueira (2014) ao focar as práticas letradas multimodais de surdos em ambientes digitais. A autora analisa vídeos produzidos e postados no YouTube por jovens surdos, demonstrando como a multiplicidade de recursos semióticos presentes nos ambientes digitais (não restritos à escrita, mas, principalmente visuais) permitem o contato desses sujeitos com diferentes linguagens e assim, tornem-se eles mesmos produtores de discursos.

Com o surgimento da internet e a disseminação das tecnologias digitais, diferentes pessoas têm hoje a possibilidade de produzir e socializar conteúdos, como vídeos, fotos, textos, e outras formas de expressão, alterando o modelo comunicacional de mídia do século XX, caracterizado pelo fluxo unidirecional (um-todos) de informações, generalizadas (e, portanto, massivas) e no controle editorial do polo emissor (Lévy, 2011). O cenário que se instaura no presente século é marcado pela emergência das mídias com funções pós-massivas, ou seja, aquelas que operam a partir da liberação do polo emissor, abrindo espaço para um fluxo informacional bi-direcional (todos-todos).

Nesse contexto, Jenkins (2009) destaca a crescente participação de indivíduos comuns na produção e distribuição de conteúdos. Alguns ambientes da internet demonstram bem tal atuação, como os blogs, redes sociais, canais de distribuição de vídeos e espaços de afinidades. Todos eles podem ser entendidos como espaços de compartilhamento e criação colaborativa de conteúdos (Shirky, 2011).

Essa participação coloca os usuários desses ambientes também na condição de autor, caracterizando assim, uma atuação resultante do envolvimento em diferentes práticas de letramentos, através do uso de diversas linguagens (escrita, imagética, sonora, gestual, entre outras). Sob essa perspectiva, Bruns (2007) argumenta que essa atuação reflete um maior empoderamento dos sujeitos e propõe o termo "produsuário" para definir sua condição híbrida de usuário e produtor. Esse produsuário é, portanto, o protagonista do letramento digital. Ele incorpora a capacidade de compreender mensagens veiculadas 
através de diversas formas de representação e de diferentes mídias, como também habilidades de expressão de ideias e pensamento também através das múltiplas formas de representação e mídias, incorporando variados sistemas semióticos na criação de significados. O modo de criação de conteúdo colaborativo por esse produsuário é denominado por Bruns de "produsagem” (2007, p. 5).

Assim sendo, as práticas de letramento digital incluem a autoria, manifestada em diferentes atividades que envolvem expressão, compartilhamento, construções interativas e colaborativas e o remix (modificações), utilizando diversas modalidades de linguagem. Para Jenkins (2009), graças a diversidade de tecnologias e semioses disponíveis hoje, multiplicam-se as formas de expressão e participação na cultura.

Conforme ressalta Rojo (2012), as atuais autorias hipermidiáticas correspondem de perto às tradicionais produções de texto. São formas de escrita e produção de significados. Isso torna-se claro, de acordo com Gee (2004), quando pensamos o letramento em termos de âmbito semiótico, ou seja, conjuntos de práticas que utilizam uma ou mais modalidades de linguagem (oral, gestual, escrita, imagens, equações, símbolos, sons, gráficos, etc.) para comunicar diferentes tipos de significados. Para esse autor, a compreensão dos significados situados em um determinado âmbito, corresponde ao ato de ler, enquanto a produção destes equivale à escrita.

Todas essas constatações chama-nos a atenção para o fato de que o desenvolvimento das competências para o letramento digital é hoje uma questão que deve ser relacionada à cidadania. Especialmente para as crianças e jovens, incluindo aqueles também com alguma deficiência, é importante que sejam garantidas as condições necessárias para que possam exercer essas novas práticas de forma crítica e ativa na sociedade. Assim como ocorre com qualquer tipo de letramento, a condição de ser letrado digitalmente está relacionada a problemas de desigualdade social. Alguns grupos na sociedade não têm acesso pleno aos meios e práticas que favorecem esse tipo de letramento, e portanto, não se beneficiam dos proveitos sociais a ele inerentes. Dentre esses, estão os surdos, cujas necessidades específicas na área da linguagem podem interferir no acesso a determinadas práticas. Surge, portanto, a demanda de se dar atenção à inserção desses sujeitos nas práticas de letramento digital, identificando como emergem os processos de significação nestes contextos, a partir das especificidades relativas à condição de ser surdo.

\section{ALGUNS RESULTADOS}

Os dados colhidos revelaram que o perfil inicial das crianças, identificado como nível básico de letramento digital, foi se alterando ao longo da pesquisa, comprovando um processo de desenvolvimento de habilidades que os colocam em direção a uma nova condição enquanto participantes ativos e críticos do letramento digital. Durante as oficinas todas as crianças se integraram em contextos comunicativos e interativos, engajaram-se em atividades de busca e análise de informações, avaliação e apropriação de conteúdos de acordo com seus objetivos, e, manifestaram práticas autorais em um espaço de afinidade (o ambiente Scratch). Dessa forma, os dados apontam pra uma ampliação das habilidades de letramento digital, demonstrando uma aproximação com os níveis superiores ao identificado no início da pesquisa.

As práticas de letramento digital que emergiram nesta pesquisa, ressaltaram aspectos importantes relacionados ao desempenho dos alunos surdos com relação a construção de significados, leitura visual e reconhecimento de padrões. Enquanto design de sentidos nos ambientes digitais e telemáticos, todos os sujeitos evidenciaram que fazem uso dos múltiplos recursos de significação disponíveis, aproveitando, assim, a multimodalidade presente nesses ambientes para manter uma atuação ativa e reflexiva. A leitura visual destacou-se, nesse processo, como forma preferencial de interação com os diferentes 
elementos semióticos, revelando possibilidades de imersão nas práticas multimodais de letramento. A aproximação com a modalidade escrita, em decorrência das demandas existentes nesses ambientes, foi marcada ainda pelo reconhecimento e uso de padrões, favorecendo processos de aprendizado dessa modalidade, à medida que esses sujeitos se inseriam em práticas interativas e significativas. Assim, observamos que o letramento digital pode favorecer o desenvolvimento de diferentes habilidades importantes para os surdos, contribuindo para a sua inclusão em práticas comunicativas e de construção de conhecimentos.

Além disso, as práticas de autoria que emergiram nesta pesquisa refletiram uma dinâmica marcada pela interatividade e colaboração. A preferência por processos autorais envolvendo a remixagem revelou ser esta a forma mais significativa e acessível de imersão na cultura da participação para esses sujeitos. Nesse processo, o exercício criativo, comunicativo e interativo propiciou o empoderamento de cada criança da condição de sujeitos-autores, exigindo-lhes e promovendo a construção da autonomia. Essa atuação resultou do envolvimento em diferentes práticas de letramento, através do uso de diversas linguagens. Marcou, portanto, uma condição centrada não apenas no papel de usuário, mas, uma iniciação importante dessas crianças como atores dos processos de produsagem que permeiam os ambientes digitais da atualidade. Como essas práticas também incluem o uso da língua escrita, portanto, também com demandas de letramento alfabético, foi possível identificar importantes evidências do uso desse sistema pelas crianças durante a experiência. Esse dado aponta a possibilidade de aprendizado dessa modalidade a partir das práticas de letramento digital, considerando que se apresenta de forma situada em evento reais e significativos. Diante dessa consideração, é importante ressaltar que não foi apenas a hipermodalidade típica dos ambientes digitais que favoreceu a interação das crianças surdas com a escrita. Somado é esse fator, certamente importante, destacou-se a perspectiva prática e criativa de imersão e interação num ambiente em que esse sistema simbólico correspondia aos interesses e objetivos das crianças. Para isso, a aproximação com o universo dos jogos digitais foi importante para configurar práticas situadas, onde era possível relacionar os conceitos aos seus significados através da percepção e da ação.

Concluímos ainda que o processo evolutivo observado se apresenta como principiante, instável ainda. A elevação entre níveis de letramento digital certamente não se dá de forma imediata e simples. Há a necessidade de fortalecimento das práticas iniciadas, de consolidação das habilidades em desenvolvimento e de estimulação de outras ainda por emergir. Mesmo assim, o grande valor do processo analisado é, sem dúvidas, a sinalização de possibilidades para esses indivíduos, muitas vezes estigmatizados como incapazes, mas que aqui se revelaram como agentes de letramentos, ativos, reflexivos e criativos. Mais do que isso, representou uma experiência que aponta para aprendizagens em multiletramentos.

\section{DESAFIOS E PERSPECTIVAS PARA A EDUCAÇÃO}

Como dito no início desse artigo, a questão do letramento dos surdos é um dos maiores desafios enfrentados pela escola. Algumas observações feitas a partir da pesquisa aqui apresentada revelam implicações diretas para o enfrentamento desse desafio.

A primeira delas diz respeito a emergência de se trabalhar o letramento digital. Essa necessidade não se restringe apenas aos alunos surdos, mas a todos os demais, uma vez que a competência para integra-se nas novas práticas multimodais, participativas e colaborativas exige dos indivíduos novas formas críticas e criativas de lidar com o conhecimento (Lankshear; Knobel, 2007). Com relação aos surdos, trata-se também de 
uma questão de garantia de acesso e participação social, evitando que se perpetue os processos que acarretam em desigualdade de oportunidades para esses indivíduos.

Uma segunda implicação importante, refere-se a constatação que as práticas letradas multimodais em ambiente digital constituem possibilidades de interação e produção de significados por parte dos surdos. Sendo assim, é possível entender que, em diferentes ambientes digitais, como espaços de afinidade, redes sociais, e outros tantos em a multimodalidade semiótica está presente, esses indivíduos encontram oportunidades de engajamento em contextos comunicativos, produtivos e de significação mais acessíveis às suas especificidades. Contudo, isso não significa que eles não encontrem barreiras para uma efetiva participação. Pelo contrário, o domínio da língua escrita é um dos desafios que muitos deles têm que enfrentar. Mas, assim como já apontado neste trabalho, a forma como a escrita se apresenta no emaranhado multissemiótico dos ambientes digitais pode contribuir para o seu aprendizado. Talvez não um aprendizado sistematizado nas estruturas normativas tradicionais da língua portuguesa. Afinal, a própria escrita da língua se altera nos espaços hipermidiáticos (interferência de outras línguas, símbolos, imagens, ícones, etc.).

Compreender tais implicações pode ser um passo importante para a escola construir propostas pedagógicas que efetivamente promovam o letramento para seus alunos surdos. Este estudo, todavia, não pretendeu apresentar um modelo a ser seguido como garantia de sucesso nessa empreitada. A intenção foi apenas recolher algumas pistas que apontem para possíveis diretrizes.

O Scratch apresenta muitas dessas pistas, assim como outros ambientes. Reúne possibilidades de interação, colaboração, criação, manipulação de conceitos e outras tantas que se multiplicam à medida que os projetos se conectam com outros ambientes e recursos.

Entretanto, a mediação do professor ainda se constitui como um dos elementos mais importantes para as propostas pedagógicas, independentemente do tipo de tecnologia usada. O professor contribui com a organização e regulação da experiência da aprendizagem, promovendo questionamentos, explicações e interações que favoreçam a obtenção dos objetivos.

Por fim, as proposições levantadas incitam novas experiências e pesquisas que possam enriquecer as análises já feitas, e, assim multiplicar nas escolas novas práticas mais adequadas à promoção de multiletramentos para surdos.

\footnotetext{
${ }^{1}$ Foi utilizada a versão 1.4 que pode ser baixada em: <http://scrtch.mt.edu/scrath_1.4/>.

2 Disponível em: <http://scratch.mit.edu/>. Os usuários do Scratch podem construir um perfil na comunidade online, compartilhar seus projetos na sua página pessoal, seguir e se comunicar com outros usuários, marcar os projetos que gosta e escrever comentários, criar estúdios temáticos, enfim, inserir-se em diversas oportunidades interativas e produtivas dentro da comunidade.
}

\section{Referências bibliográficas}

ALVES, L. R. G. Letramento e games: uma teia de possibilidades. Educação \& Tecnologia, Centro Federal de Educação Tecnológica de Minas Gerais, v. 15, n.2, jun. 2010. Disponível em: <http://seer.dppg.cefetmg.br/index.php/revista-et/article/view/272>. Acesso em: 26 jun. 2014.

ARCOVERDE, R. D. de L. Tecnologias digitais: novo espaço interativo na produção escrita dos surdos. Cadernos CEDES, Campinas, v. 26, n.69, p.251-267, mai./ago. 2006. Disponível em: <http://www.scielo.br/pdf/ccedes/v26n69/a08v2669.pdf>. Acesso em 20 jun. 2014. 
ARAÚJO, M. D. V.; FRADE, I. C. A. da S. Cultura escrita impressa e cultura escrita digital: a perspectiva de crianças de camadas médias. Língua Escrita, UFMG, Belo Horizonte, n. 2, p. 2944, dez. 2007.

BRUNS, A. Produsage, Generation C, and Their Effects on the Democratic Process. In: MEDIA IN TRANSITION CONFERENCE, 5, 2007, Boston. Anais. Boston: MIT, 2007. Disponível em: <http://eprints.qut.edu.au/7521/>. Acesso em 22 jul. 2014.

COPE, B.; KALANTZIS, M. Multiliteracies: new literacies, new learning. Pedagogies: An International Journal, University of Illinois Urbana-Champaign, v. 4, n. 3, p. 164-195, jul. 2009. Disponível em: <http://newlearningonline.com/_uploads/pedagogiesm-litsarticle.pdf>. Acesso em 23 ago. 2014.

DIONISIO, A. P. Gêneros multimodais e multiletramentos. In: KARWOSKI, A. M.; GAYDECZKA, B.; BRITO, K. S. (org.). Gêneros textuais e reflexão e ensino. Rio de Janeiro: Parábola Editorial, 2006. p. 131-143.

FERNANDES, S. F. Prática de letramento na educação bilíngue para surdos. Curitiba: SEED, 2006.

GESUELI, Z. M. A escrita como fenômeno visual nas práticas discursivas de alunos surdos. In: LODI, A. C. B.; MÉLO, A. D. B. de; FERNANDES, E. (Org.) Letramento, bilinguismo e educação de surdos. Porto Alegre: Mediação, 2012. p. 173-186.

GEE, J. P. Lo que nos enseãn los videojuegos sobre el aprendizaje y el alfabetismo. Málaga: Ediciones Aljibe, 2004.

JENKINS, H. Cultura da Participação. 2 ed. São Paulo: Aleph, 2009

JENKINS, H. et al. Confronting the challenges of participatory culture: media education for the 21st century. Chicago: MacArthur Foundation, 2009. Disponível em <http://www.macfound.org/media/article_pdfs/JENKINS_WHITE_PAPER.PDF $>$. Acesso em 24 ago. 2014.

KLEIMAN, A. B. (Org.). Os significados do letramento: uma nova perspectiva sobre a prática social da escrita. Campinas: Mercado de Letras, 2010.

KRESS, G. Recognizing learning: a perspective from a social semiotic theory of mulimodality. In: SAINT-GEORGES, I. de; WEBER, J. J. Multilingualism and Multimodality: current challenges for educational studies. Rotterdam: Sens Publishers: 2013. p. 119-132. Disponível em: <http://eprints.ncrm.ac.uk/3202/>. Acesso em 22 jul. 2014.

LANKSHEAR, C.; KNOBEL, M. Sampling "the new" in new literacies. In: (Eds.). A new literacies sampler. New York: Peter Lang, 2007. p. 1-24.

LÉVY, P. Cibercultura. 3. ed. São Paulo: Editora 34, 2011.

MACEDO, R. S. A etnopesquisa crítica e multirreferencial nas ciências humana e na educação. 2 ed. Salvador: EDUFBA, 2004.

MACHADO, F. M. A.; FELTES, H. P.M. Comunidade surda e redes sociais: práticas de regionalidade e identidades híbridas. Conexão - Comunicação e Cultura, UCS, Caxias do Sul, v. 9, n. 17, jan./jun. 2010. Disponível em: <http://www.ucs.br/etc/revistas/index.php/conexão/ article/viewFile/469/391>. Acesso em: 20 jun. 2014. 
NOGUEIRA, A. S. Práticas de Letramento multimodais em Ambiente digital: uma possibilidade para repensar a educação de surdos. Revista Intercâmbio, LAEL/PUCSP, v. 28, p. 19-45, 2014. Disponível em: <http://revistas.pucsp.br/index.php/intercambio/article/view/19639/14513>. Acesso em 05 set. 2014.

RIBEIRO, A. E. Letramento Digital: um tema em gêneros efêmeros. Revista ABRALIN, Belém, v. 8, n. 1, p. 15-38, jan./jun. 2009. Disponível em:

<http://http://www.abralin.org/site/data/uploads/revistas/2009-vol-8-n-1/anaelisa.pdf >. Acesso em: 24 ago. 2014.

ROJO, R. Pedagogia dos multiletramentos: diversidade cultural e de linguagens na escola. In: ; MOURA, Eduardo (org.). Mulltiletramentos na escola. São Paulo: Parábola Editorial, 2012. p. 11-31.

ROSA, A. da S.; CRUZ, C. C. Internet: fator de inclusão da pessoa surda. Revista Online da Biblioteca Prof. Joel Martins, Campinas, v. 2, n. 3, jun. 2001, p. 38-54. Disponível em: < http://www.fae.unicamp.br/revista/index.php/etd/article/view/1889/1730>. Acesso em 25 jun 2014.

SHIRKY, C. A Cultura da Participação: criatividade e generosidade no mundo conectado. Rio de Janeiro: Zahar, 2011.

SOARES, M. Novas Práticas de Leitura e Escrita: Letramento na Cibercultura. Educação \& Sociedade, Campinas, v. 23, n. 81, p. 143-160, dez. 2002. Disponível em:

<http://www.scielo.br/scielo.php?script=sci_arttext\&pid=S010173302002008100008\&lng=em> . Acesso em 24 ago. 2014.

XAVIER, A. C. dos S. Letramento digital e ensino. In: SANTOS, C. F.; MENDONÇA, M.

(Org.). Alfabetização e Letramento: conceitos e relações. Belo Horizonte: Autêntica, 2007. p. 133-148. 